\title{
Comment on "Prevalence of hot flashes in women of 40 to 65 years of age with metabolic syndrome"
}

\author{
Rong $\mathrm{Hu}^{1} \oplus$, Zhongguo Ren²*
}

Dear Editor,

We were very pleased to read the article "Prevalence of hot flashes in women of 40-65 years of age with metabolic syndrome" by Sau and colleagues ${ }^{1}$. In this study, the authors revealed that hot flashes are highly prevalent among women older than 40 years and appear to be associated with metabolic syndrome (MetS). The occurrence of hot flashes may be a risk marker for MetS. However, some concerns should be raised from our point of view.

First, this was a cross-sectional study based on information obtained from 7212 women who were followed up in 2014 via the Family Health Program in the city of Pindamonhangaba (Brazil). A potential for selection bias exists; out of 1435 women who were initially recruited, 513 women who did not complete the questionnaire and who were employed for the calculation of the Kupperman index were excluded from the study.
Our suggestion is that all 7212 women who were followed up in 2014 should be included in this study.

Second, the authors mentioned that multiple logistic regression models were constructed to estimate the relative weight of each independent variable after adjustment for skin color, income, depression, anxiety, and smoking in the Statistical calculations section. However, we did not find any analysis on skin color, income, depression, anxiety, and smoking status among the women included. Additionally, the scale for evaluation of anxiety and depression should be described in detail in the Methods section.

\section{AUTHORS" CONTRIBUTIONS}

RH: Data curation, Formal Analysis, Writing - original draft. ZR: Conceptualization, Writing - review and editing.

\section{REFERENCE}

1. Sau HPF, Schmitt ACB, Cardoso MRA, Aldrighi JM. Prevalence of hot flashes in women of 40 to 65 years of age with metabolic syndrome. Rev Assoc Med Bras. 2020;66(12):1628-32. https:// doi.org/10.1590/1806-9282.66.12.1628

\footnotetext{
'Geriatrics, The People's Hospital of China Three Gorges University - Yichang, Hubei 443000, China.

2Department of Anesthesiology, The People's Hospital of China Three Gorges University - Yichang, Hubei 443000, China.

*Corresponding author: rongrongdoctor@126.com

Conflicts of interest: the authors declare there are no conflicts of interest. Funding: none.

Received on August 08, 2021. Accepted on August 11, 2021.
} 